\title{
Potencial impacto del libre comercio sobre la educación en Colombia
}

\author{
Orlando Vaca M¹, Fernando Díaz, MSc ${ }^{2}$ \\ ${ }^{1}$ Investigador de la Fundación FUNZHE. Miembro de la Alianza de la Sociedad Civil por un Comercio Justo \\ ${ }^{2}$ Economista Universidad Jorge Tadeo Lozano \\ Recibido: 07-07-04 / Aceptado: 08-11-04
}

Introducción. El avance de la integración mundial no se limita al comercio propiamente dicho, abarca todas las esferas de la actividad humana incluyendo la educación. Despojada de la categoría de derecho adquirido, ésta se ha transformado en servicio; desde las guarderías hasta los centros de posgrado, todos los niveles de acceso a la formación e instrucción, son considerados potenciales mercados. Para comprender el impacto sobre la educación y la generación de conocimiento, de las negociaciones comerciales que adelanta Colombia con otros países, veamos cuales son los capítulos que se relacionan con ésta.

Principios de libre comercio: echando abajo derechos adquiridos. Los borradores del ALCAy del TLC incluyen unos principios guía, que sirven de derrotero a seguir por las partes negociadoras. El principio rector general aboga porque el concepto de "libre comercio" deba aplicarse a todas las esferas de los Estados parte del tratado. Tal concepto exige echar por tierra cualquier norma, proyecto de norma o articulado que obstaculice el libre comercio (1).

El segundo principio rector de las negociaciones comerciales es el del trato nacional, que supone la igualdad de condiciones para las empresas extranjeras para competir con las nacionales en la oferta de bienes y servicios. A primera vista, este postulado protegería la igualdad en el acceso a los mercados; sin embargo, al considerar la enorme capacidad de lobby y autofinanciamiento con que cuentan las multinacionales, se hace evidente que apunta a

Correspondencia: ovacam@hotmail.com favorecer su accionar y, extendiendo el razonamiento al principio general de prevalencia del "libre comercio", demuestra que la asimetría entre los países, hace que la igualdad en el trato sea pactado entre no iguales, favoreciendo al más fuerte.

Acceso a mercados: servicios escenciales en la mira. Los países menos desarrollados de América ofrecen mercados de bienes muy limitados, la baja competetividad en la producción de maquinaria, manufacturas o tecnología, hacen que sus mejores mercados son aquellos relacionados con los servicios que brinda el Estado a sus comunidades, tales como salud y saneamiento básico, educación básica, educación pública superior, formación laboral; además de agua potable, energía eléctrica y otros, denominados generalmente "servicios públicos". Los países de América Latina, para garantizar su desarrollo y fortalecer la capacidad del Estado para garantizar a sus comunidades el acceso a los servicios, han desarrollado normativas que protegen tales áreas y permiten que la redistribución de la riqueza se exprese a través de mecanismos de subsidio que permiten que los menos favorecidos accedan gradualmente a condiciones de desarrollo (2), blindando constitucionalmente el reconocimniento a los derechos fundamentales, muy en contravía del concepto neoliberal de "servicios básicos y/o escenciales". Tal adversidad ha sido denunciada recurrentemente por organizaciones civiles nacionales e internacionales, dado que:

Inhibe a los gobiernos de poder tomar medidas que garanticen el acceso a la salud, la política de 
«quien paga recibe» imperaría. Especialmente ataca el concepto de derecho, imponiendo el de «servicio». Esta intención ha sido catalogada como la «mercantilización de los derechos fundamentales, principalmente el de la vida».

De este modo, echa abajo el concepto de los Derechos Económicos Sociales y Culturales y al Desarrollo (DESC-D), sustituyéndolo por «Venta de Servicios», con las implicaciones legales que eso conlleva, pues pondría toda reclamación en términos de Derecho Comercial ALCA (3).

La fuerte penetración de instituciones privadas en el mercado de venta de servicios educativos en países que adelantaron tratados bilaterales una década atrás, ha ido en detrimento de la oferta pública de los mismos, llevando rapidamente a restringir el acceso sobre la base de la capacidad de pago (4). Igualmente, ha puesto bajo control extranjero una valiosa infraestructura producto de décadas de aplicación de esquemas solidarios de financiamiento, tanto en redes de suministro de energía, agua potable o comunicaciones; como en la oferta de servicios educativos.

Compras del Estado. Todas las contrataciones y adquisiciónes que hace el Estado son materia de negociación en los acuerdos comerciales bilaterales y multilaterales, esta categoría cobija tanto a los servicios públicos esenciales (educación y salud, por ejemplo). Las pretensiones

“...sobre trato nacional, trato de nación más favorecida, especificaciones técnicas y requisitos de proveeduría podría poner a cuestionamiento un amplio espectro de reglas importantes sobre adquisiciones relacionadas al desarrollo económico y social, y la protección de derechos humanos, laborales y ambientales, y parece que persisten desacuerdos mayores en cuanto a como tratar adquisiciones por instancias sub nacionales y si excluir o incluir temas tradicionales de autoridad pública, tales como los servicios sociales y la educación"(5).
El acceso a la educación pone en juego elementos tales como el financiamiento, la infraestructura, la contratación de personal administrativo y docente, la implementación de la logística general, la compra de ordenadores y el diseño de redes informáticas, entre muchos otros. Generalmente, los gobiernos contratan estos servicios bajo el criterio de la promoción del trabajo nacional mediante cuotas de contratación y trato preferencial a los proveedores internos; sin embargo, las pretenciones de las compañías multinacionales proveedoras de servicios se dirijen hacia el derrumbe de las regulaciones internas para el acceso a estos mercados, poniendo en peligro, desde la estabilidad laboral de docentes y administrativos, hasta la autonomía de los estados para la definición de políticas educativas basadas en el interés interno de cada país, supeditándolos a los apetitos de los inversionistas más fuertes, en este caso las multinacionales.

Educación como mercado. La demanda estimula la oferta, las familias que necesitan dejar bajo cuidado a sus bebés mientras asisten a sus trabajos; los niños y niñas que cada año llegan a la edad escolar, quienes llegan a edad universitaria o inician sus posgrados; todos ellos hacen parte de un "mercado" que exige altas contrataciones estatales (6). Éstas se hallan en la mira de los inversionistas, quienes ofrecen suplir espacios que los gobiernos no alcanzan a cubrir, mediante convenios, franquicias y subvenciones, que en principio no son adversos, salvo porque los más fuertes blindan sus inversiones mediante mecanismos de solución de controversias que evaden las leyes nacionales, dejando de lado el control a que la ciudadanía tiene derecho.

En el caso de las guarderías, la educación básica primaria, la educación media y la formación técnica, existe una fuerte presión para entregar la oferta de servicios a empresas privadas mediante esquemas de concesión, contratación, dación de bienes para administración privada, etc. 
“Chile, por ejemplo, privatizó gran parte de sus instituciones educacionales a instancias del Banco Mundial, a raíz de lo cual en los últimos veinte años el estado redujo el gasto en educación en un $32 \%$ aproximadamente. No es de extrañar, por tanto, que en este lapso de tiempo el rendimiento escolar en los sectores acomodados haya mejorado y que en los sectores pobres haya descendido. Como señala la organización Education International, «subordinar la educación a las fuerzas del mercado bien podría hacerla menos accesible y agravar la desigualdad social» (7).

Sin embargo, es en la educación superior donde se concentran los riesgos, dado que combina una serie de factores que la hacen un mercado apetecible:

1. Cuenta con infraestructura que abarca laboratorios, bibliotecas, centros de investigación, museos, pequeñas plantas para el desarrollo de productos.

2. Fuertes contrataciones estatales en materia de inversión para la investigación, subsidio al acceso, pago de nóminas, etc.

3. Producción de conocimientos útiles, prácticos, aplicables, generados por centros de investigación que abarcan áreas que van desde la filosofía y la política, pasando por lo social, administrativo, derechos fundamentales, hasta el desarrollo de tecnologías aplicables a la producción agripecuaria o a los procesos industriales de pequeña y mediana escala, que corresponden al desarrollo de nuestras economías.

4. Sólida relación con la empresa privada nacional y con las comunidades, mediante centenares de proyectos en donde docentes - investigadores, alumnos, técnicos, logistas, etc., junto con los habitantes de municipios, barrios o veredas, analizan, diagnostican y plantean solución a problemas en la administración o en la producción, generando conocimientos útiles y aplicables.

5. Incidencia en el segmento etáreo más prometedor, la juventud. Los jóvenes reunen condiciones atractivas como mercado pues estarán allí durante 5 o más años. Un porcentaje considerable aspirará a posgrados, maestrías, especializaciones y doctorados; servicios mucho más costosos que el pregrado. Además, los jóvenes son más creativos, cuentan con mayor intención investigativa, enlazan rápidamente el análisis con la práctica, desarrollan tecnologías y conocimientos útiles y están más abiertos a la apropiación de nuevas tecnologías.

Así pues, el control financiero sobre los centros educativos deriva en el acceso a muchas puertas hacia los negocios.

En los países menos desarrollados que han pactado acuerdos comerciales con otros más avanzados, el impacto de la acción combinada de los principios rectores del libre comercio, con los capítulos que favorecen el ingreso al mercado de "universidades trasnacionales", se ha manifestado en presiones para reducir el pregrado, focalizar el conocimiento en aras de una mayor oferta en el mercado de los posgrados, echar abajo la estabilidad laboral de docentes e investigadores en función de permitir el ingreso de profesionales extranjeros sin mayores restricciones, reducir la capacidad del Estado de vigilar a la universidad, supeditar el acceso a los servicios universitarios a quienes tengan capacidad de pago, manejar el mercado del crédito educativo, etc.

En muchas ocasiones, la aplicación de estas medidas ha convertido a los centros educativos locales en especies de "maquilas" del conocimiento, al servicio de transnacionales de la educación, en donde el centro docente local se encarga del "enganche" de clientes, al tiempo que la trasnacional se queda con los derechos de propiedad intelectual generados, los convenios de financiamiento, las contrataciones estatales de servicios educativos y un mercado amarrado de posgrados. Todo esto sin contar los convenios privados, las operaciones por medio de fundaciones, el acceso a subvenciones internacionales $\mathrm{y}$, ante todo, 
la definición de pénsums por fuera de la regulación estatal local.

El conocimiento, ¿en manos de quien?. Los acuerdos de comercio, que concretan la actual tendencia de la globalización, contienen como plato fuerte las normas de propiedad intelectual, que se relacionan con la educación superior, dado que cuentan como eje central a las patentes.

La financiación y apoyo a los centros de investigación y a los proyectos de grado implican la cesión de los derechos de propiedad intelectual de lo allí investigado, dejando en manos de terceros el desarrollo de productos, la comercialización de los mismos y la posibilidad de desarrollar productos de segundo orden o derivados de los primeros, como una cadena de mercado (8).

Así, el proceso mediante el cual se financian investigaciones, se detectan nichos de conocimiento susceptibles de ser soporte de planes financieros de largo aliento, el desarrollo de productos derivados de las investigaciones, las innovaciones, las creaciones, los métodos aplicados, los productos de segundo orden, etc., están directamente relacionados con los derechos de propiedad intelectual, escenario en donde se sintetiza el poder del conocimiento, pues quien domina no es quien produce conocimiento, sino el dueño de la patente.

Conclusiones. Este artículo plantea retos importantes para el sector educativo frente a las negociaciones comerciales que adelanta el gobierno colombiano y el potencial impacto de las mismas en materia de soberanía para la definición de políticas educativas, prevalencia de derechos constitucionales, garantía de apropiación y uso del conocimiento generado en Colombia, protección y fortalecimiento de la educación pública, vigilancia de la calidad de la misma, fortalecimiento de la financiación para las investigaciones, etc.
No se trata de oponerse a la inserción de nuestro país en los escenarios internacionales, sino de hacerlo partiendo de la protección y fortalecimiento de la producción de conocimiento, tan valorada por la ciudadanía y tan desprotegida ante estas tensiones. Están en juego,desde la estabilidad laboral, pasando por el acceso a la educación pública, los contratos relacionados con la prestación de servicios educativos, las adquisiciones de bienes, servicios y consultorías, la definición de los pénsums, hasta la soberanía en materia de políticas educativas. Frente a estos retos cabe preguntarse ¿Hay conciencia y conocimiento sobre las implicaciones, retos y oportunidades que el escenario proximo plantea?, ¿Se han trazado planes de contingencia y competencia frente al eventual ingreso al mercado de verdaderas trasnacionales de los servicios educativos?, ¿Qué dice el Ministerio de Educación sobre el tema?, ¿Quién protege los derechos de nuestra comunidad científica?. Queda un largo camino por recorrer y el tiempo apremia, pero el primer paso debe ser la valoración y el reconocimeinto de que Colombia no es una cenicienta del saber, todo lo contrario.

\section{Referencias}

1 Borradores del ALCA y/o texto del TLCAN. En URL:http: www.ftaa-alca.org

2 Gratius S. El proyecto del ALCA visto desde Europa. FES Chile: Instituto de Estudios Iberoamericanos (IIK) en Hamburgo: 2001 $75 \mathrm{p}$.

3 Hansen-Kuhn K. The Development GAP. Alliance for Responsable Trade; 2001. 35 p.

4 Encuentro Hemisférico de Lucha Contra el ALCA. Los derechos humanos y el Área de Libre Comercio de las Américas. Otra América es posible. 2003

5 Vaca Melo O. Alianza de la Sociedad Civil por el Acceso a la Salud y a los Medicamentos en Colombia. En URL: http:// usuarios.lycos.es/accesosalud

6 Confederación de Trabajadores de la Educación de la Republica Argentina. ¿Porque decimos no al ALCA, si a la educación pública?. La Habana.; 2001.

7 Alianza Social Continental. El Proyecto del ALCA y los Derechos de los Inversionistas "un TLCAN Plus" - Un Análisis del Borrador del Capítulo de Inversiones del ALCA - Capítulo 2. Mecanismos de solución de controversias. 2001. Disponible en URL: http://www.asc-hsa.org.

8 Holguin Zamorano G. Alca y Tlc: los verdaderos efectos sobre el acceso a la salud. Mision Salud; 2003. 52p. 